\title{
Extracranial-intracranial bypass grafts
}

\author{
G. KHODADAD
}

From the Department of Neurosurgery, University of Pennsylvania Medical School, and the Department of Surgery, Pennsylvania Hospital, Philadelphia, Pennsylvania, U.S.A.

SUMMARY An extracranial-intracranial bypass graft was established in 16 dogs. The graft wag routed deep in the lateral pharyngeal space as opposed to the subcutaneous course in front of the ear, which may be hazardous. Of 10 common carotid-middle cerebral arterial bypass grafts three were still patent four and a half, six, and 11 months postoperatively. The remaining seven arterial an\& six venous bypass grafts were occluded either at the first angiogram 1 to 14 days after the operatiofe or at the second angiogram 4 to 9 weeks later. The low patency rate in this experiment is attributeథథ to the very small external diameter (average $0.8 \mathrm{~mm}$ ) of the recipient artery, to donor-recipient discrepancy, to spasm and possibly oedema of the graft. To our knowledge this is the first report ow patent extracranial-intracranial bypass grafts in a laboratory animal.

There is a selective group of stroke patients that may be benefited by a bypass vein graft from the cervical carotid artery to the supraclinoid carotid artery. Among these are patients who have a history of transient ischaemic attacks (TIAs) or multiple small strokes, and their carotid angiograms show complete occlusion of one internal carotid and stenosis of the contralateral carotid artery. Surgery upon a completely occluded artery, especially if the occlusion is of long-standing, is not usually successful, and only in $20 \%$ of the vessels can an active flow be established (Thompson, Austin, and Patman, 1967). Surgery upon the stenotic carotid artery in some of these patients may also be complicated by a partial or a complete stroke even when an internal shunt has been used at the time of surgery (Ojemann and Austen, 1968). In these circumstances, one may attempt to establish a bypass graft on the side of complete occlusion before repairing the stenotic vessel.

Sometimes TIAs or strokes develop not due to the cervical or intracranial vascular disease but because of the occlusive disease of the cavernous carotid artery (Marshall, 1971). In some of these patients an extracranial-intracranial bypass graft may also be considered. The potential therapeutic value of this procedure encouraged us to carry out experimental studies to evaluate the possibility of maintaining longterm patency of extracranial-intracranial bypass grafts.

\section{METHODS}

Large mongrel dogs weighing $70 \mathrm{lb}(32 \mathrm{~kg})$ or $\mathrm{m}$ were anaesthetized with sodium pentobarbital inid intubated. The animal was cooled to $28^{\circ} \mathrm{C}$ by surfaces hypothermia. Under six- or 10-fold magnification with a Zeiss operating microscope a graft 15 to 20 gni long was isolated from either a saphenous vein of saphenous artery. The external diameter of former varied from 2.5 to $3.5 \mathrm{~mm}$ and the latterv from 1.5 to $2.5 \mathrm{~mm}$. One common carotid artery was isolated. Ipsilateral to the exposed common carotid artery a $10 \mathrm{~cm}$ vertical incision was made it the temporozygomatic region and the zygomatio arch was removed. The temporalis and massete muscles were incised vertically, and a trephine hole
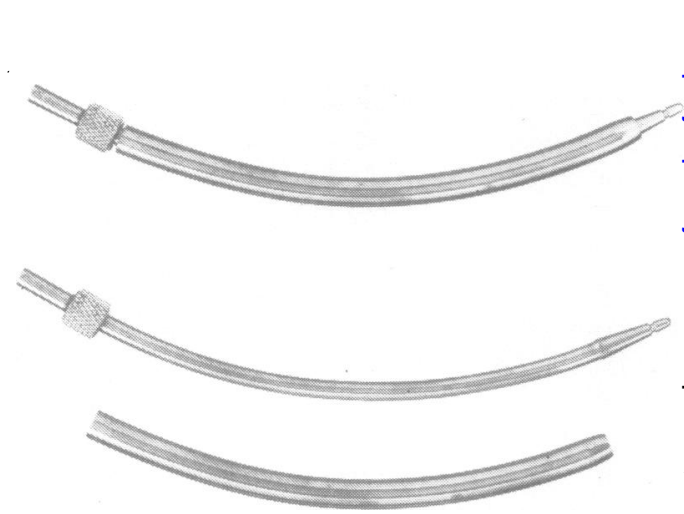

FIG. 1. From above down are the assembled bypass guide, carrier, and cannula. 
was made in the exposed temporal bone. For better exposure of the temporal bone it was often necessary to keep the dog's mouth wide open by tightly rolled gauze sponges. This manoeuvre lowered the mandible, which usually overlay the lower temporal region. The trephine was enlarged and the dura mater was elevated from the floor of the middle fossa. The floor of the middle fossa was removed medially to the foramen ovale; the dura mater was incised and the middle cerebral artery exposed. Initially, attempts were made to expose the supraclinoid carotid artery and establish an anastomosis at this site. As, however, the supraclinoid carotid artery was found to be only 2 or $3 \mathrm{~mm}$ long, which made the procedure very difficult, it was abandoned.

The graft was excised from the leg and transferred to the neck. A bypass cannula with carrier (Fig. 1) was passed from the floor of the middle fossa into the neck through the lateral pharyngeal space. The graft was connected to the carrier in the neck and drawn into the intracranial cavity within the cannula and with care to prevent rotation, the cannula was then removed. A 2 or $3 \mathrm{~mm}$ transverse incision was made in the common carotid artery immediately proximal or distal to the cranial (superior) thyroid artery and the proximal end of the graft was anastomosed end to side to the common carotid artery under six- or 10-fold magnification using 9-0 monofilament nylon suture. A major branch of the middle cerebral artery was isolated for a $10 \mathrm{~mm}$ distance and occluded with two clips (Khodadad, 1967). The external diameter of this vessel varied

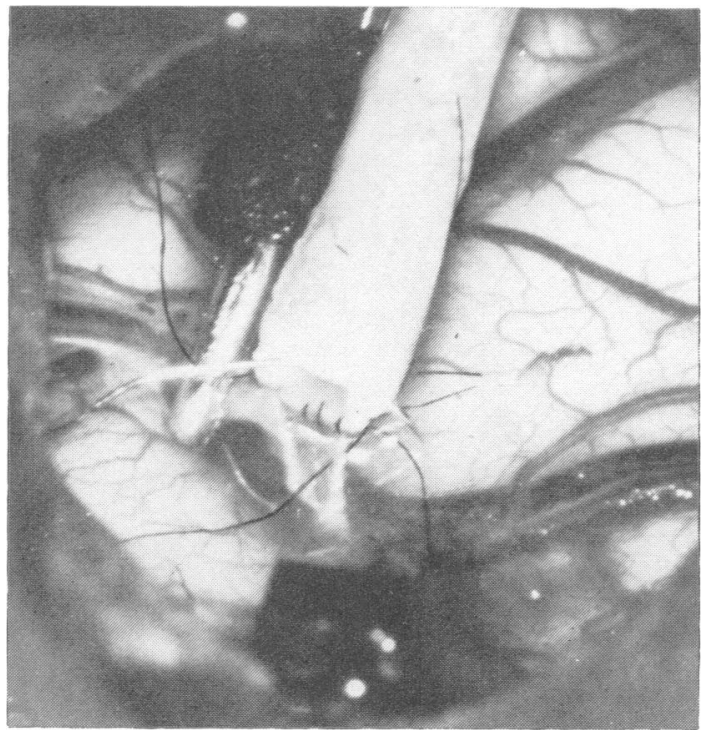

FIG. 2. An end-to-side anastomosis of a saphenous vein graft and a middle cerebral artery branch. Magnification $\times 16$. from 0.6 to $1.2 \mathrm{~mm}$. A 2 to $3 \mathrm{~mm}$ longitudinal incision was made in the artery and under 16- or 25-fold magnification the distal end of the graft was anastomosed end to side to the middle cerebral branch (Fig. 2). The clamps were then removed and circulation re-established. The occlusion time of the middle cerebral branch varied from 1.5 to four hours. The common carotid artery was ligated distal to the anastomosis in all but four animals. In three of these dogs the graft was anastomosed to the trunk of the middle cerebral artery and the trunk was ligated proximal to the graft. The remaining graft was anastomosed to the middle cerebral artery branch and neither the middle cerebral artery nor the common carotid artery was ligated. Before completion of the distal anastomosis hypothermia was terminated and surface warming was applied until the temperature reached $38^{\circ} \mathrm{C}$. Anticoagulants were not used. The patency of the grafts was evaluated by open common carotid angiography.

\section{RESULTS}

Among the 20 dogs operated on, two animals died during the operation from an overdose of anaesthesia. Two animals died shortly after the operation from ventricular fibrillation or aspiration. Of the remaining 16 animals, 10 had arterial grafts and six had vein grafts. The first angiograms revealed five patent arterial grafts and three patent but narrowed and irregular vein grafts. The remaining five arterial grafts and three vein grafts were occluded. At the second angiogram only three of the five initially patent arterial grafts remained patent and all of the remaining vein grafts were occluded. The patent arterial grafts, however, were still patent in a third angiogram carried out $4 \cdot 5,6$, and 11 months postoperatively (Fig. 3). The intervals between operation and angiography and the patency of the grafts are summarized in Tables 1 and 2.

Only one animal in the series exhibited neurological signs in the postoperative period. It had a bypass vein graft from the right common carotid artery to the trunk of the middle cerebral artery and the latter was ligated proximal to the graft. This animal recovered from anaesthesia but remained sleepy and inactive for three days. Within six days from the operation the animal could walk but with a tendency to fall to the left. It had frequent Jacksonian seizures on the left. The left-sided weakness and seizures gradually subsided and within three weeks from operation the animal was normal except for mild weakness in the left extremities. Carotid angiography done 
TABLE 1

ARTERIAL GRAFTS

\begin{tabular}{|c|c|c|c|c|c|c|c|c|c|}
\hline No. & $\begin{array}{l}\text { lst angiogram, } \\
\text { days after surgery }\end{array}$ & Patent & $\begin{array}{l}\text { 2nd angiogram, } \\
\text { weeks after surgery }\end{array}$ & Patent & $\begin{array}{l}\text { 3rd angiogram, } \\
\text { months after surgery }\end{array}$ & Patent & $\begin{array}{l}\text { Distal site of } \\
\text { anastomosis }\end{array}$ & $\begin{array}{l}\text { Common } \\
\text { carotid } \\
\text { ligated }\end{array}$ & $\begin{array}{c}\text { Middle } \\
\text { cerebral } \\
\text { ligated }\end{array}$ \\
\hline 1 & 1 & Yes & 9 & No & - & - & MCB & No & No \\
\hline 2 & 8 & No & - & - & - & - & MCB & Yes & No \\
\hline 3 & 7 & Yes & 8 & Yes & 11 & Yes & MCB & Yes & No \\
\hline 4 & 14 & No & - & - & - & - & MCB & Yes & No \\
\hline 6 & 4 & Yes & 5 & Yes & 6 & Yes & MCB & Yes & No \\
\hline 7 & 6 & No & - & - & - & - & MCB & Yes & No \\
\hline 8 & 2 & Yes & 7 & No & - & - & $\mathrm{MCT}$ & No & Yes \\
\hline 9 & 13 & Yes & 6 & Yes & $4 \cdot 5$ & Yes & $\mathrm{MCB}$ & Yes & No \\
\hline 10 & 9 & No & - & - & - & - & MCB & Yes & No \\
\hline
\end{tabular}

$\mathrm{MCB}=$ middle cerebral branch. $\mathrm{MCT}=$ middle cerebral trunk.

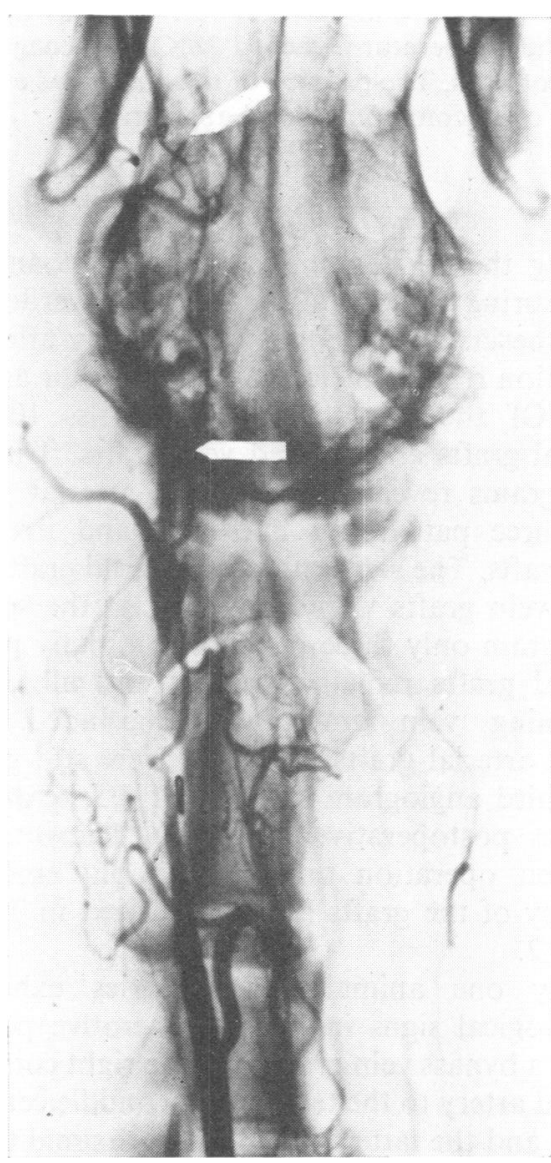

FIG. 3a. An anteroposterior view of a right common carotid angiogram showing a bypass arterial graft from the common carotid artery to the anterior branch of the middle cerebral artery 11 months postoperatively. The silver clip in the lower left shows the site of cervical anastomosis. The upper arrow points to the site of cranial anastomosis. Interruption of the common carotid artery above the graft prevents the location of carotid ligation. The distal carotid artery is filled by newly developed collateral branches.

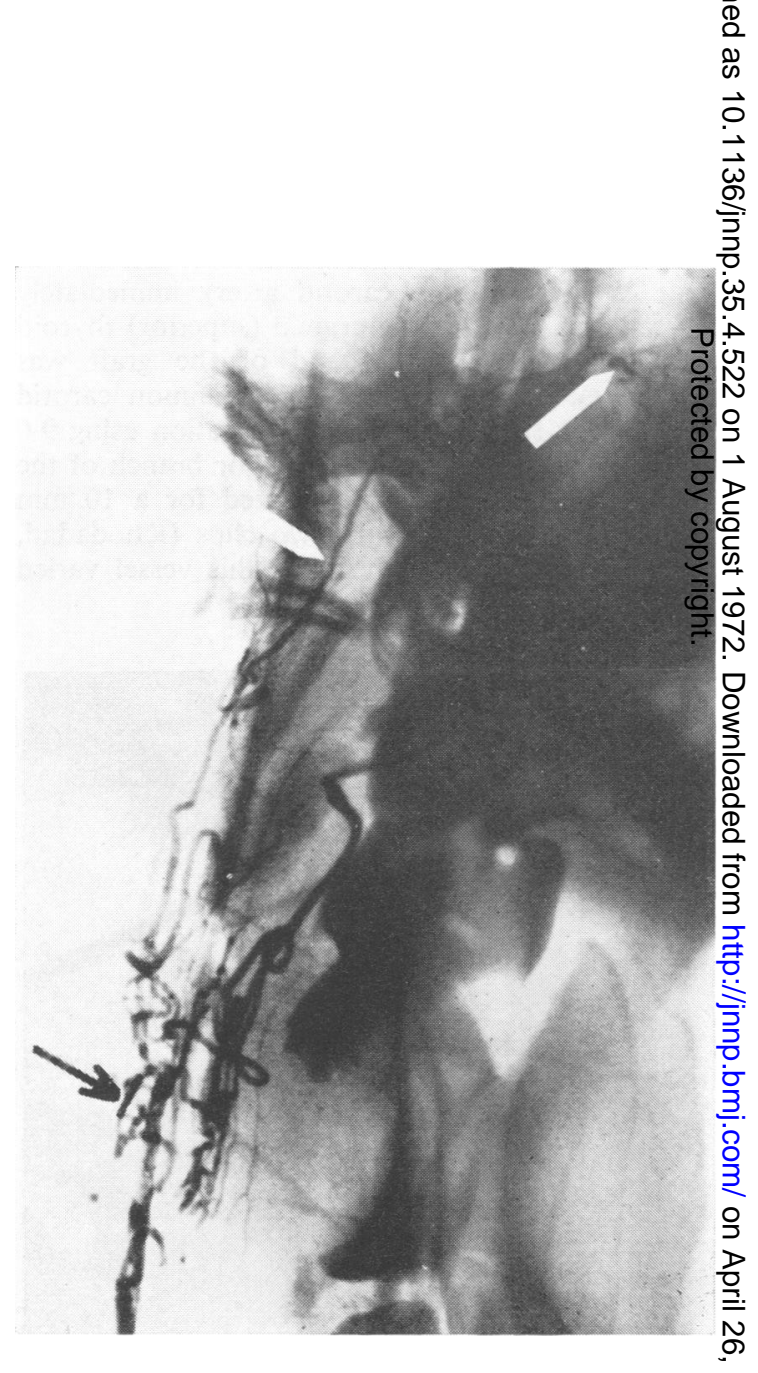

FIG. 3b. A lateral right common carotid angiogram $\tilde{O}$ of the same animal as in Fig. 3a showing the bypass graft. The black arrow points to the silver clip placedo near the cervical anastomosis and the upper white arrow shows the site of cranial anastomosis. 


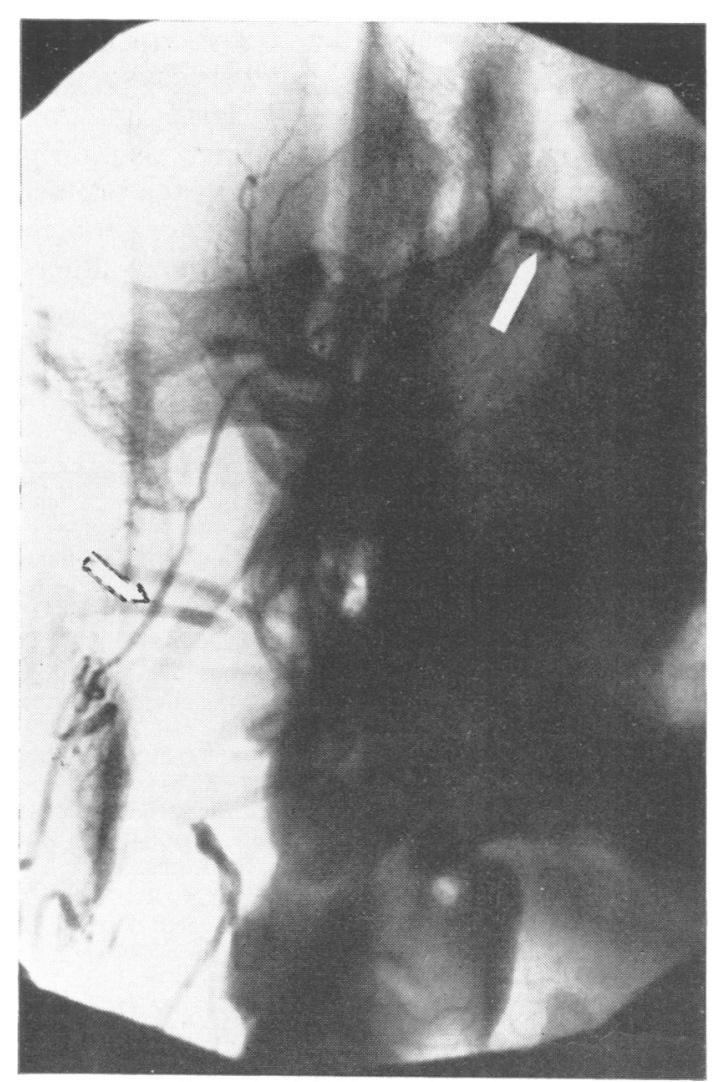

FIG. 3c. A lateral magnification angiogram of the same animal as in Figs 3a and 3b.

10 days postoperatively showed occlusion of the graft (Table 2, no. 4).

In two other animals with grafts anastomosed to the trunk of the middle cerebral artery and ligation at the trunk proximal to the graft (Tables 1 and 2, nos. 8 and 3 ) angiography two and four days postoperatively showed patent grafts. Seven weeks after surgery both grafts were occluded. No neurological deficit was noticed in these animals before or after the graft became occluded, probably because of adequate collateral circulation.

\section{DISCUSSION}

Yasargil (1967) used a $12 \mathrm{~cm}$ graft from the saphenous artery to connect the common carotid to the middle cerebral artery in three dogs. The graft was passed subcutaneously in front of the ear and was anastomosed end-toend to the middle cerebral artery. All the grafts were occluded four to eight weeks after surgery. He concluded that the vessels thrombosed because vascularization of such a long transplanted artery was not possible in a short period of time. In our experiments three arterial grafts, longer than those used by Yasargil, remained patent for several months. These results suggest that revascularization of the graft is not as great a problem as Yasargil has assumed.

It has been shown that the nutrition of a bypass vein graft is maintained by 'plasmic' circulation during the first 48 hours and later by capillary circulation which is re-established by 72 hours (Wyatt, Rothnie, and Taylor, 1964). Since there are similarities between the behaviour of a vein graft and an arterial graft, their nutritional requirements may also be alike.

Lougheed, Marshall, Hunter, Michel, and Sandwith-Smyth (1971) attempted to insert a bypass vein graft from the cervical carotid artery to the intracranial carotid artery in two patients, but in both cases the procedure could not be completed because of the degree of atherosclerosis present in the supraclinoid carotid artery. Recently, however, they described success in a patient with relatively normal supraclinoid carotid artery.

Both Yasargil and Lougheed used a subcutaneous route in front of the ear to carry the

TABLE 2

VEIN GRAFTS

\begin{tabular}{|c|c|c|c|c|c|c|c|}
\hline No. & $\begin{array}{l}\text { Ist angiogram, } \\
\text { days after surgery }\end{array}$ & Patent & $\begin{array}{l}\text { 2nd angiogram, } \\
\text { weeks after surgery }\end{array}$ & Patent & $\begin{array}{l}\text { Distal site of } \\
\text { anastomosis }\end{array}$ & $\begin{array}{c}\text { Common carotid } \\
\text { ligated }\end{array}$ & $\begin{array}{c}\text { Middle cerebral } \\
\text { ligated }\end{array}$ \\
\hline 1 & 8 & No & - & - & MCB & Yes & No \\
\hline 2 & 1 & Yes & 10 & No & MCB & Yes & No \\
\hline 3 & 4 & Yes & 7 & No & MCT & No & Yes \\
\hline 4 & 10 & No & - & - & MCT & No & Yes \\
\hline 5 & 2 & Yes & 5 & No & MCB & Yes & No \\
\hline 6 & 12 & No & - & - & MCB & Yes & No \\
\hline
\end{tabular}

\footnotetext{
$\mathrm{MCB}=$ middle cerebral branch $. \mathrm{MCT}=$ middle cerebral trunk.
} 
graft from the neck to the intracranial cavity. This exposes the graft to external pressure and trauma. The lateral pharyngeal approach used in this study may provide better protection against these possible hazards.

In the present study, apart from the very small size of the recipient artery, which complicated the patency of the grafts, there were two or three other factors which were thought to be also responsible for postoperative occlusion. The diameter of the vein graft was usually three to four times larger than the diameter of the middle cerebral artery branch. This luminal discrepancy caused stasis in the graft and predisposed it to thrombosis. There was much less discrepancy in the lumen diameter of the arterial graft and the recipient artery.

The spasm and possibly oedema which developed during dissection and isolation of the graft were other contributing factors. If the external diameter of the artery was $1.5 \mathrm{~mm}$ or less the spasm almost occluded the lumen. Gentle mechanical dilatation with folded fine wire or local application of papaverine did not relieve the spasm. Isolation of the vein graft also caused some spasm but, because of the relatively large lumen and thin media, the lumen of the graft always appeared large enough to carry an adequate volume of blood. Spasm of the middle cerebral artery and its branches occurred but did not seem to be responsible for occlusion of the graft.
In human surgery, the degree of donorrecipient discrepancy is small because intracranial arteries are relatively large and vein grafts of proper size are obtainable. Also, owing to the general use of the vein graft, the problem $\stackrel{\overline{0}}{\mathrm{C}}$ of spasm is not anticipated. The major problem, however, appears to be the amount of atherosclerosis involving cerebral arteries.

\section{REFERENCES}

Khodadad, G. (1967). New clip for intracranial surgery and vascular microsurgery. Journal of Neurosurgery, 26, 448449.

Lougheed, W. M., Marshall, B. M., Hunter, M., Michel, E. R., and Sandwith-Smyth, H. (1971). Common carotid to intracranial internal carotid bypass venous graft. $\infty$ Technical note. Journal of Neurosurgery, 34, 114-118.

Marshall, J. (1971). Angiography in the investigation of ischaemic episodes in the territory of the internal carotid artery. Lancet, i, 719-721.

Ojemann, R. G., and Austen, W. G. (1968). Surgical treatment of extracranial occlusive vascular disease. In NeuroOphthalmology. Symposium of the University of Miami and the Bascom Palmer Eye Institute. Vol. 4, 388-404. W Edited by J. Lawton Smith. Mosby: St. Louis.

Thompson, J. E., Austin, D. J., and Patman, R. D. (196\%. if Endarterectomy of the totally occluded carotid artery f $N$ stroke. Results in 100 operations. Archives of Surgery, 9 용 음
$791-801$.

Wyatt, A. P., Rothnie, N. G., and Taylor, G. W. (1964). The vascularization of vein-grafts. British Journal of Surgen, \ 51, 378-381.

Yasargil, M. G. (1967). Experimental small vessel surge in the dog including patching and grafting of cerebral vessels and the formation of functional extra-intracrani $i$ shunts. In Microvascular Surgery, pp. 87-126. Edited R. M. P. Donaghy and M. G. Yasargil. Mosby: Saint Louis. 